\title{
Uterus Masajlarının \\ Kadınların Postpartum Ağrı Şiddetini Algılamasındaki Etkisi
}

Effect of Uterine Massage in the Perception of Women's Postpartum Pain Intensity

\section{Zümrüt BİLGİN ${ }^{1}$, Nuran KÖMÜRC ${ }^{2}{ }^{2}$}

1. Marmara Üniversitesi, Sağlık Bilimleri Fakültesi, İstanbul

2. İstanbul Aydın Üniversitesi, Sağlık Bilimleri Fakültesi, İstanbul

\section{ÖZET}

Amaç: Araştırma, uterus masajlarının kadınların postpartum ăgrı şiddetini algılamasındaki etkisini belirlemektir.

Gereç ve Yöntem: Bir ĕgitim ve araştırma hastanesi'nde A ğustos 2015-Kasım 2015 tarihleri arasinda toplam (50 transabdominal dairesel fundus masajı grubu=TDFMG, 50 transabdominal bimanuel fundus masajı grubu=T$B F M G$ ve 50 kontrol grubu=KG) 150 kadin randomize kontrollü olarak standardize edildi. Kadınlar; 18-37 yaş arasında, 37.-41. gebelik haftasında, sistemik hastalığl, uterusu aşırı geren bir riski ve gebelik komplikasyonu olmayan, doğum ve doğum sonu herhangi bir komplikasyon gelişmeyen spontan vajinal doğum yapanlar şeklinde standardize edildi. Girişimli (forseps veya vakum) doğum yapan, kollum lesarasyonu, postpartum analjezik alan olgular çalışma dışı bırakıldı. Araştırmada kadınlara eylemin latent fazında uygulama ile ilgili bilgilendirme yapılıp onay alındıktan sonra her üç gruba "Gebe Tanitım Bilgi Formu”, "Doğum Sonu Görüşme ve İzlem Formu” ve kadınların ağrı algılamasını belirlemek için "Vizüel Analog Skala [Visual Analog Scale (VAS)]” (postapartum 1., 2., 6.saatte) uygulandr.

Her üç gruba postpartum dönemde standart hemşirelik bakımı verildi ve deney gruplarına farklı olarak postpartum birinci saatin sonunda $5 \mathrm{kez}$ (15 dakikada bir ve 60 saniye süren) uterus masajı uygulandl.

Bulgular: Kadınların \%78'inin uterus masajının kendilerini rahatlattığını ve postpartum ikinci saatteki ağrl şiddetini algılama (VAS) puan ortalaması açısından gruplar arasında anlaml fark olduğu belirlenmiştir $(p<0,05)$. Plasentanın çıkarılma şekli ile kadınların postpartum 6.saatteki VAS puanı ortalamasi arasindaki farkin anlamlı olduğu belirlenmiştir $(p<0,05)$. Beden kitle indeksi (BKI) ile kadınların postpartum 2.-6.saatteki VAS puanı ortalaması arasındaki farkın anlamlı olduğu saptanmıştır $(p<0,05)$. Uterus masajı uygulanan kadınların daha az postpartum ă̆rı deneyimledikleri en az ă̆rl algılayan grubun ise TBFMG'u olduğu belirlenmiştir.

Sonuç: Araştırmamızda, uterus masajı uygulanan kadınların postpartum dönemde daha az ağri deneyimlediği saptanmiştır.

Anahtar Kelimeler: uterus masajl; postpartum ăgrl; şiddeti algllama; etkisi

\section{İletişim Bilgileri:}

Sorumlu Yazar: Zümrüt BİLGIN

Yazışma Adresi: Marmara Üniversitesi, Sağlık Bilimleri Fakültesi, İstanbul, Türkiye

E-posta: zumrutbilgin45@gmail.com

Makalenin Geliş Tarihi: 08.01.2016

Makalenin Kabul Tarihi: 23.01.2016

DOI: http://dx.doi.org/10.16948/zktb.86700

\section{ABSTRACT}

Objective: The research aims to find out effect of uterine massage in the perception of women's postpartum pain intensity.

Material and Method: Total of 150 women (50 trans abdominal circular fundus massage TDFMG, 50 trans abdominal bimanuel fundus massage TBFMG and 50 control group $C G$ ) were checked and randomly standardized in a research and training hospital. A standardized group of women chosen from age between 18-37, who is in maternity week without a systematic disease and a pregnancy complication that excessive tensioning the uterus, in addition, spontan vaginal birth who does not have any birth and after-birth complication. Incidents with Interference birth (forceps or vacuum) or collum laceration, and who had analgesic postpartum are out of scope for the research. In the latent phase of research women were informed and asked for their approval then, the forms were filled out for all three groups as follows; "Pregnant Information Form", "Postpartum Interview and Follow-up Form". In addition, to determine women's pain perception, Visual Analog Scale (VAS) was applied within postpartum 1st, 2nd and 6th hours.

All three groups were provided by standard postpartum nursing care, and given massage 5 times at the end of the 1st hour (in every 15 minutes for 60 seconds duration) that differs from each other for every group.

Results: $78 \%$ of women stated that a uterus massage relieved them and there was a significant difference in 2nd hour's VAS points between the groups $(p<0.05)$. In addition, there was a substantial correlation between the method of taking out placenta and 6th hour postpartum pain $(V A S)$ the average sensing $(p<0.05)$. The difference between body mass index (BMI) and 2-6th hours postpartum pain the average sensing (VAS) was substantive. The women who were provided by a uterus massage, experienced less postpartum pain and the group TBFMG had the least postpartum pain.

Conclusion: The research shows that, the women provided by a uterus massage had experienced less pain in postpartum period.

Keywords: uterus massage; postpartum pain; level perception; effect

Bilgi: Bu araştırma Marmara Üniversitesi (MÜ) Să̆lık Bilimleri Enstitüsü'nde 2015 yılında yapılmış olan 10095770 sayll tezden kaynaklanmaktadir. 


\section{GİRIŞ}

Postpartum dönemde kadınlar değişik düzeylerde ağrı deneyimleyebilir. Ağrı kadının duygusal durumunu etkiler ve şiddetli ağrı ise anksiyete nedeni olabilir. Ağrı, subjektif bir semptom olmasına karşın kadınlar postpartum ağrının şiddetini tanımlayabilir [1].

Postpartum dönemdeki ağrı genelllikle, uterusun hizlı ve aralıklı kasılmasından kaynaklanır. Multipar kadınlar uterus tonusü kaybı nedeniyle daha çok ağrı deneyimleyebilir. Buna karşılık, primiparların uterusu sürekli kasıldığından postpartum ağrı deyimlemesi yaygın değildir $[2,3,4]$. Postpartum ağrı bazen doğum ağrısıdan daha da kötüdür. Ağrı sırtın altında ve karında hissedilir. Genellikle doğumdan sonra iki-üç gün bazen bir hafta sürmektedir [1, 4]. Literatürde kadınların \%80,0'inin postpartum bir hafta devam eden ağrı deneyimledikleri bildirilmiştir [5].

Postpartum dönemde yaşanan ağrıyı hafifletme ve gidermede farmakolojik ve non-farmakolojik yöntemler kullanılmaktadır. Farmakolojik yöntem olarak analjezikler yaygın kullanılır. Non-farmakolojik yöntemler ise masaj, 1s1 paketleri, buz paketleri, hipnoterapi, akupunktur ve transkütanöz elektriksel sinir stimülasyonu (TENS)'dur [1, 4]. Ayrıca analjeziklerle birlikte kadının yüzükoyun ya da bacaklarını karnına çekerek bir süre yatması (uterusu sıkıștırmanın) ağrıyı azaltmada etkili olduğu bildirilmiştir [2]. Ancak postpartum dönemde kadınların klinik ortamda yüzükoyun yatması pek mümkün olmamaktadır. Kadın sırt üstü pozisyonda iken uterus masaj1 yoluylada uterusa bas1/sıkıştırma uygulanabilir. Uterus masajı doğum sonu kliniklerinde sik uygulanan bir yöntemdir [7]. Uluslararası Ebelik Konfederasyonu (ICM) ve Uluslararasi Jinekoloji ve Obstetrik Federasyonu (FİGO), uterus kontraksiyonları artırmak için plasentanın doğumundan sonra uterus masajının yapılmasını önermektedir [8]. Uterus masaj1 TDFM ve TBFM şeklinde uygulanır ve her iki masajı kadın kendisine uygulayabilir. TBFM ile uterusa bası/sıkıştırma yöntemiyle kadının yüzükoyun yattığı durumdaki etki sağlanmaya çalışılır [2, 4, 9]. Son y1llarda doğum sürecinin girișimlerle bozulması, doğal bir süreç olan doğum sonu dönemini de etkilediğinden uterus masajının postpartum dönemde yaşanan ağrıyı azaltması ve kadının konforuna olumlu yönde etkilemesi açısından yararlı olabilir. Non-farmokolojik ağrı kontrol yöntemleri bugün pek çok ülkede, kadın sağlığının farklı aşamalarında etkili ve basit olmaları nedeniyle sikça kullanılmaktadır $[10,11]$. Sahada kullanım şansı görmesine rağmen bu yöntemlerin etkinliğini ortaya koyan kanıt düzeyi yüksek araştırma örnekleri çok azdır. Bu araştırma; uterus masajlarının kadınların postpartum ağrı şiddetini algilamasındaki etkisini belirlemek amacıyla yapılmış randomize kontrollü bir çalişmadır.

\section{GEREÇ ve YÖNTEMLER}

Araştırma bir eğitim ve araștırma hastanesi'nde Ağustos 2015-Kasim 2015 tarihleri arasında gerçekleştirildi. Araştırmanın yapılabilmesi için öncelikle araștırmanın yapıldığg hastanenin etik kurulundan izin ve kurum onay1 alınmıştır. Kadınlardan araştırmaya katılmayı kabul ettiklerine dair yazılı onam alınd1. Araştırmanın evrenini ilk ve ikinci doğumunu yapmak için başvuran ve normal spontan vajinal doğum yapan tüm kadınlar oluşturdu. Örneklemini ise araștırma ölçütlerine uyan, bilgilendirilmiş onam formunu imzalayan kadınlardan TDFMG 50, TDFMG 50 ve hastane protokolüne göre standart bakım alan $\mathrm{KG}$ oluşturan 50 kadın olmak üzere toplam 150 kadın oluşturdu. Kadınlar; 18-37 yaş arasında, 37.-41. gebelik haftasında, sistemik hastalığı olmayan, herhangi bir gebelik komplikasyonu olmayan (aşırı uterusu geren sorun, plasenta previa, preeklampsi, erken membran rüptürü vb.), doğum ve doğum sonu herhangi bir komplikasyon gelişmeyen spontan vajinal doğum yapanlar şeklinde standardize edildi. Girişimli (forseps veya vakum) doğum yapan, kollum lesarasyonu, postpartum analjezik alan olgular çalışma dış1 bırakıldı. Araştırma ile ilgili kadınlara eylemin latent fazında bilgilendirme yapılıp onay alındiktan sonra her üç gruba "Gebe Tanıtım Bilgi Formu", "Doğum Sonu Görüşme ve İzlem Formu", ve kadınların postpartum ağrı şiddetini belirlemek için "Vizüel Analog Skala [Visual Analog Scale (VAS)]" uygulandı [12]. Her üç gruptaki kadına postpartıum standart hemşirelik ve ebelik bakımı verildi. Deney gruplarına kontrol grubundan farklı olarak postpartum uterus masaj1 uyguland1.

Kadınlar araştırmaya alınma ölçütleri açısından değerlendi ve kabul ettikleri belirlendikten sonra randomizasyon yapıldı. Araştırmaya katılacak olan kadınlar rastlantısal olarak randomizasyon yöntemi ile numara sirasına göre üç gruba ayrildı. Birinci sırada dairesel fundus masajı grubu (TDFMG), ikinci sirada tarsabdominal fundus masajı grubu (TBFMG), üçünü sirada kontrol grubu (KG) olacak şekilde belirlendi ve örneklem sayısına ulaşıncaya kadar işleme devam edildi. Ölçütlere göre uygun olmayan kadınlar çalışma dışı bırakıldı. Veriler, gebe tanıtım bilgi formu (kadınların sosyodemografik ve obstetrik özellikleri ile ilgili sorulardan), 
doğum sonu görüşme ve izlem formu (kadınların doğum sonu dönemdeki duygusal ve fiziksek durumu ve gereksinimleri,anne bebek etkileşimi, ağrısı, kendini nasıl hissettiği ve uterus masaj1 uygulamasindan rahatsız olma durummuna ilişkin sorulardan oluştu) $\mathrm{Bu}$ formlar postpartum ilk 3 saatte lohusa odasinda 6.saatte ise doğum sonu kliniğinde uyguland. Postpartum VAS deney gruplarına postpartum 1.saatte (masaj ugulanmadan), 2.saatte (toplam $5 \mathrm{kez}$ masaj uygulandiktan sonra) ve 6.saatte, kontrol grubuna ise postpartum 1., 2., 6.saatte uyguland1. Kadınlara VAS gösterilerek yaşadıkları ağrıya hiç ağrı yok " 0 ", en şiddetli ağr1 "10" olacak şekilde kaç puan verdikleri sorularak kendi ağrılarının şiddetini değerlendirmeleri istendi. Araştırmada kullanılan verilerin tamamı araştırmacı tarafından yüz yüze görüşme yöntemiyle topland1.

Uterus masajının uygulanması: Kadınlar sirt üstü pozisyonda ve bacakları dizlerinden hafif bükülmüș șekilde yatırıldı. Birinci gruptakilere, uterusun fundusu elle tespit edildikten sonra uterus fundusuna dairesel hareketlerle masaj (TDFM) uyguland. İkinci gruptakilere uterusun fundusu hissedildi ve uterus fundusu iki el arasında sıkıștırıldı (TBFM) (internal uterus masajınının eksternel olarak uygulanması). Masaja postpartum birinci saatte başlandı ve toplam $5 \mathrm{kez}$ (15 dakikada bir 60 saniye süren) uterus masaj1 yapıldı. Uterus masajı uygulaması sirasında kadının masajdan rahatsız olmamasına dikkat edildi. Ayrıca kadının yaşam bulguları (hasta başı mönitör ve dijital 1sı ölçer) değerlendirildi. Ayrıca masajın uygulanmadığ 1 sürelerde kadınlar, beslenmeleri ve bebeklerini emzirmesi için desteklendi. Veri toplama aşa- masında 224 kadına ulaşıldı ancak ölçütlere uymayan vakalar değerlendirmeye alınmadı ve toplam 150 kadının verileri değerlendirildi.

İstatistiksel Analiz: Araştırmadan elde edilen veriler bilgisayar ortamında Statistical Package for Social Sciences (SPSS) for Windows 17.0 istatistik paket programı kullanılarak değerlendirildi. Kadınlara yönelik tanımlayıcı bilgiler sayı, yüzde dağılımları ortalama ve standart sapma şeklinde verildi. Deney ve kontrol grubundaki kadınların sosyo-demografik ve doğurganlık özelliklerinin, doğum ve sonuna ilişkin özelliklerin benzer bir dağılım gösterip göstermediğini belirlemek amacı ile Ki-kare (Chi-Square) testi yapıld1. Uterus masaj1 ve kontrol grubundaki kadınların postpartum ağrı düzeyleri ve gruplar arasında fark olup olmadiğ 1 , t testi ve One-Way ANOVA testi ile degerlendirildi. Verilerin istatistiksel anlamlilık durumu $\mathrm{p}<0,05$ düzeyinde yorumland1 [13].

\section{BULGULAR}

Araştırmaya katılan kadınların yaş ortalaması $(24,74 \pm 4,31)$ yı1, \%54,7'sinin 18-24 yaş aralığında, \%48,7'sinin ortaokul/lise mezunu, \%14,7'sinin çalıştığı, \%10,7'sinin gebeliğinde sigara kullandığı, \%65,3'ünün 40-41.gebelik haftasında ve tüm kadınların gebeliğinde ortalama $14,05 \pm 5,53 \mathrm{~kg}$ aldığ 1 ve kadınların tan1tıcı özelliklerinin benzer olduğu saptanmıștır ( $>00,05)$. Her üç gruptaki kadınların \% 78,7'sine doğumda fundal bası, \%84,0'üne epizyotomi uygulandığ $\%$ \%2,0'sinin perine-periüretra bölgede leserasyon (epizyotomiye bağli) oluştuğu ve gruplar arasındaki farkın anlamlı olmadığ belirlenmiştir ( $p>0,05)$. Tablo 1'de her üç grup-

\begin{tabular}{|c|c|c|c|c|c|c|c|c|c|}
\hline \multirow{2}{*}{ Fiziksel ve Duygusal Durumu } & \multicolumn{2}{|c|}{ TDFMG $(n=50)$} & \multicolumn{2}{|c|}{ TBFMG $(n=50)$} & \multicolumn{2}{|c|}{$K G(n=50)$} & \multicolumn{2}{|c|}{ Toplam ( $n=150)$} & \multirow{2}{*}{$\begin{array}{l}x^{2} \text { ve } p \\
\text { Değeri }\end{array}$} \\
\hline & $\mathrm{n}$ & $\%$ & $\mathrm{n}$ & $\%$ & $\mathrm{n}$ & $\%$ & $\mathrm{n}$ & $\%$ & \\
\hline \multicolumn{10}{|l|}{ Fiziksel Durumu } \\
\hline Çok İyi & 27 & 55,1 & 17 & 34,0 & 18 & 36,7 & 62 & 41,9 & \multirow{2}{*}{$\begin{array}{c}x^{2}=5,004 \\
p=0,099\end{array}$} \\
\hline Halsiz/ Yorgun & 23 & 46,0 & 33 & 66,0 & 32 & 64,0 & 88 & 58,7 & \\
\hline \multicolumn{10}{|l|}{ Duygusal Durumu } \\
\hline Mutlu & 31 & 62,0 & 32 & 64,0 & 38 & 76,0 & 101 & 67,3 & \multirow{2}{*}{$\begin{array}{c}x^{2}=2,607 \\
p=0,302\end{array}$} \\
\hline Stresli/Hüzünlü/Ağlamaklı & 19 & 38,0 & 18 & 36,0 & 12 & 24,0 & 49 & 32,7 & \\
\hline \multicolumn{10}{|l|}{ Anne Bebek Etkileşimi } \\
\hline İyi & 48 & 96,0 & 48 & 96,0 & 48 & 96,0 & 144 & 96,0 & \multirow{2}{*}{$* *$} \\
\hline Desteğe Gereksinimi Var & 2 & 4,0 & 2 & 4,0 & 2 & 4,0 & 6 & 4,0 & \\
\hline \multicolumn{10}{|l|}{ Annenin Destek Gereksinimi $* * *$} \\
\hline Yok & 27 & 54,0 & 17 & 34,0 & 33 & 66,0 & 77 & 51,3 & \multirow{3}{*}{$\begin{array}{c}X^{2}=12,106 \\
p=0,017\end{array}$} \\
\hline Fizyolojik gereksinim & 20 & 40,0 & 28 & 56,0 & 12 & 24,0 & 60 & 40,0 & \\
\hline Duygusal gereksinim & 3 & 6,0 & 5 & 10,0 & 5 & 10,0 & 13 & 8,7 & \\
\hline \multicolumn{10}{|l|}{ Perine Ağrısı } \\
\hline Yok & 9 & 18,0 & 4 & 8,0 & 19 & 38,0 & 32 & 21,3 & \multirow{2}{*}{$\begin{array}{c}x^{2}=13,904 \\
p=0,001^{*}\end{array}$} \\
\hline Var & 41 & 82,0 & 46 & 92,0 & 31 & 62,0 & 118 & 78,7 & \\
\hline
\end{tabular}


taki kadının \%58,7'inin doğum sonu kendini iyi hissettiğini, \%32,7'si stresli-hüzünlü-ağlamaklı olduğunu, çoğunluğunun (\%96) anne bebek etkileşiminin çok iyi olduğu, kadınların \%40'nın fizyolojik (hijyen, beslenme vb.), \%8,7'sinin duygusal (eşini ve ailesini görmek) gereksinimi ve $\% 78,7$ 'sinin perine bölgesinde ağrısı olduğu saptanmıştır. Kadınların destek gereksinimi ve perine bölgesi ağrısı açısından gruplar arasındaki farkın anlamlı olduğu $(\mathrm{p}<0,05)$, kadının fiziksel, duygusal durumu ve anne bebek etkileşimi açısından grupların benzer olduğu saptanmiştır ( $\mathrm{p}>0,05$ ) (Tablo 1).

Tablo 2'de postpartum birinci ve altınc1 saatteki postpartum ağrı şiddetini algılama (VAS) puanı ortalamaları açısından gruplar arasında istatistiksel açıdan fark yokken ( $p>0,05)$, ikinci saatteki VAS puanı ortalaması açısından gruplar arasındaki farkın anlamlı olduğu belirlenmiştir $(\mathrm{p}<0,05)$ (Tablo 2).

Tablo 3'de kadınların plasentasının çıkarılma şekli ile postpartum VAS puanı ortalamalarının karşılaştırılması görülmektedir. Plasentanın çıkarılma şekli ile postpartum 1.-2.saatteki VAS puanı ortalamaları arasındaki farkın an-

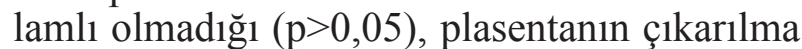
şekli ile postpartum 6.saatteki VAS puan1 ortalamaları arasında istatistiksel açıdan anlamlı fark olduğu belirlenmiştir $(p<0,05)$ (Tablo 3$)$.
Tablo 4'de kadınların Beden Kitle İndeksi (BKI) ile postpartum 1.saatteki VAS puanı ortalamaları arasındaki farkın anlamlı olmadığ $(p>0,05)$, BKİ ile postpartum 2.-6.saatteki VAS puanı ortalamaları arasındaki farkın istatistiksel açıdan anlamlı olduğu belirlenmiştir $(p<0,05)$ (Tablo 4).

\section{TARTIŞMA}

Postpartum ağr1, "stres ve anksiyete" yan1tı oluşturarak kadının konforunu olumsuz yönde etkilediği bilinmektedir. Postpartum şiddetli ağrı algısı kadınların süreçteki rolünü etkiler. Çoğu multipar kadının postpartum ağrı deneyimlediği belirtilmektedir [14].

Çalışmaya katılan her üç gruptaki kadının $\% 58,7$ 'inin doğum sonu kendini iyi hissettiği, \%32,7'si stresli-hüzünlü-ağlamakli olduğu, çoğunluğunun $(\% 96,0)$ anne bebek etkileşiminin çok iyi olduğu, \%8,7'sinin duygusal (eșini ve ailesini görmek) gereksinimi ve \%78,7'sinin perine bölgesinde ağrisı olduğu ve perine bölgesi ağrısı açısından gruplar arasında anlamlı fark olduğu belirlenmiştir ( $\mathrm{p}<0,05$ ) (Tablo 1).

Normal spontan vajinal doğum sonrası kadınların \%68,0'inin postpartum 1-2 hafta ağrı deneyimledikleri ve ağrının etkin yönetimi için ağrı şiddetini belirlemek gerektiği belirtilmiştir [1]

\begin{tabular}{|c|c|c|c|c|c|c|c|}
\hline \multirow{2}{*}{ VAS Puanı } & \multicolumn{2}{|c|}{ TDFMG $(n=50)$} & \multicolumn{2}{|c|}{ TBFMG $(n=50)$} & \multicolumn{2}{|c|}{ KG $(n=50)$} & \multirow{2}{*}{ F ve $p$ Değeri } \\
\hline & $X \pm S S$ & Min-Max & $X \pm S S$ & Min-Max & $X \pm S S$ & Min-Max & \\
\hline DS 1. St* & $2,68 \pm 2,28$ & $0,00-8,00$ & $2,08 \pm 2,53$ & $0,00-8,00$ & $3,08 \pm 2,65$ & $0,00-10,00$ & $2,032 / 0,135$ \\
\hline DS 2. St* & $1,74 \pm 1,77$ & $0,00-7,00$ & $0,64 \pm 1,19$ & $0,00-4,00$ & $1,42 \pm 1,91$ & $0,00-8,00$ & $5,834 / 0,004 *$ \\
\hline DS 6. St* & $0,84 \pm 1,28$ & $0,00-5,00$ & $0,34 \pm 1,09$ & $0,00-7,00$ & $0,50 \pm 1,03$ & $0,00-4,00$ & $2,490 / 0,086$ \\
\hline
\end{tabular}

$F=$ One-Way ANOVA testi ve $p<0,05$ anlamli; *DS: Doğum Sonu; St: Saat

\begin{tabular}{|c|c|c|c|c|}
\hline \multirow{3}{*}{\multicolumn{2}{|c|}{ VAS Ölçüm Zamanı }} & \multicolumn{2}{|c|}{ Plasentanın Çıkarılma Şekli } & \multirow{3}{*}{ t ve $p$ Değeri } \\
\hline & & \multirow{2}{*}{$\begin{array}{c}\text { Aktif traksiyon } \\
\text { X } \pm \mathrm{SS}\end{array}$} & \multirow{2}{*}{$\begin{array}{c}\text { Spontan } \\
X \pm S S\end{array}$} & \\
\hline & & & & \\
\hline \multirow{3}{*}{ VAS Puanı } & Postpartum 1. St* & $2,50 \pm 2,45$ & $3,11 \pm 2,77$ & $-1,121 / 0,264$ \\
\hline & Postpartum 2. St* & $1,21 \pm 1,59$ & $1,50 \pm 2,21$ & $-0,764 / 0,446$ \\
\hline & Postpartum 6. St* & $0,42 \pm 0,91$ & $1,19 \pm 1,83$ & $-2,074 / 0,048^{*}$ \\
\hline
\end{tabular}

$t=$ testi ve $p<0,05$ anlamli; *St: Saat

Tablo 4. Grupların Beden Kitle Indeksi ile Ağrı Algısı Ortalamasının Karşılaştırılması.
\begin{tabular}{|l|l|c|c|c|c|}
\hline \multirow{2}{*}{ VAS Ölçüm Zamanı } & \multicolumn{3}{c|}{ Beden Kitle Indeksi } \\
\cline { 2 - 5 } & BKi 18,5-25 & BKi 26-30 & BKi 31 ve 个 \\
\hline \multirow{3}{*}{ VAS Puanı } & Postpartum 1.saat & $2,46 \pm 2,67$ & $1,96 \pm 0,38$ & $1,06 \pm 0,20$ \\
\cline { 2 - 5 } & Postpartum 2.saat & $2,67 \pm 2,54$ & $1,51 \pm 0,16$ & $0,069 / 0,933$ \\
\cline { 2 - 5 } & Postpartum 6.saat & $2,59 \pm 2,39$ & $1,80 \pm 0,27$ & $1,56 \pm 0,24$ \\
\hline
\end{tabular}


Postpartum birinci ve altınc1 saatteki VAS puanı ortalamaları açısından gruplar arasında fark yokken $(p>0,05)$, ikinci saatteki VAS puanı ortalamaları açısından gruplar arasındaki fark anlamlidir $(p<0,05)$ (Tablo 2). TBFM uygulanan kadınların daha az ağrı algılamasının, onların postpartum olumlu deneyim yaşamasında önemli olduğu düşünülmüştür. Ramasamy ve Suzan (2014) çalışmalarında deney grubundaki primipar kadınların, \%86,6'sının hafif ağrısı, $\% 13,3$ 'ünün orta düzeyde ağrisı olduğununu, kontrol grubundaki primipar kadınların ise $\% 46,6$ 'sının orta düzeyde ağrısı ve $\% 53,3$ 'nün şiddetli ağrısı olduğunu belirlemişlerdir [1]. Damrongrucktham ve ark. (2009) abdominal cerrahi sonrasi hastalara 0., 30., 90., 150. dakikalarda gerçek el refleksoloji ve mimic el refleksolojisi uygulamış, gerçek el refleksoloji uygulanan grupta ağrı düzeyinin anlamlı olarak daha düşük olduğunu saptamışlardır [15].

Araştırmamızda plasentanın çıkarılma şekli ile ile postpartum 1.-2.saatteki VAS puan1 ortalamaları arasındaki farkın anlamlı olmadığı $(p>0,05)$, plasentanın çıkarılma şekli ile postpartum 6.saatteki VAS puanı ortalamaları arasındaki farkın istatistiksel olarak anlamlı olduğu belirlenmiştir $(p<0,05)$ (Tablo 3). Jangsten ve ark. (2005) yaptıkları çalışmada deney grubu (erken kordon klempleme, oksitosinin enjeksiyonu, kontrollü kord traksiyonu uygulanan) ile yalnız klinik bakım alan kadınların postpartum ağrı algılama durumunu karşılaştırmış, deney grubunda olanların \%28,0'inin, kontrol grubunda olanların ise \%31,0'inin ağr1 deneyimlemediklerini belirlemişler [16]. Araştırmamıza katılan kadınların ağrıya ilișkin sonuçlarına bakıldığında masajın postpartum ağrı ile başetmede etkin ve kullanışlı yöntem olduğu düşünülebilir.

Kadınların BKİ ile postpartum 1.saatteki VAS puanı ortalamaları arasındaki farkın anlamlı olmadığı $(p>0,05)$, BKİ ile postpartum 2.-6. saatteki VAS puanı ortalamaları arasındaki farkın istatistiksel olarak anlamlı olduğu belirlenmiştir $(p<0,05)$ (Tablo 4). Mogren (2006) çalışmasında kadınların \%43,1'inde doğum sonrası alt1 ay kalıc1 bel ağrısı ve pelvik ağrı yaşadığını bildirmiştir.

Gebeliğin erken döneminde ağrısı olan, ileri anne yaşı ve yükssek BMI' $i$ olan kadınların daha fazla bel ve pelvik ağrı yaşadığı, BMI'nin yanı sıra hipermobilitenin gebelik sonrası kalıcı ve belirgin ağrının belirleyicisi olduğu bildirilmiştir [17, 18]. Özdemir ve ark. (2013) Malatya il merkezinde yaşayan bireylerde boyun, sirt ve bel ağrısı prevalansları ve etkileyen faktörler ile ilgili çalışmalarında BKİ ile bel ağrısı arasında anlamlı bir ilișkinin olduğunu saptamışlardır $(p<0,05)$. Prevalans ise fazla kilolu ve şişmanlarda daha yüksek bulunmuştur [19]. BKİ ile postpartum ağrı arasında ilişki olduğu ve sonuçlarımızın literatür ve diğer örneklem sonuçları ile desteklendiği anlaşılmıştır.

\section{SONUÇ}

$\mathrm{Bu}$ araştırmada, postpartum dönemde uterus masaj1 uygulanan grupların (TDFMG ve TBFMG) kontrol grubuna göre postpartum ağr1 şiddetini daha az algıladığı/hissettiği ve uterus masajdan çok az kadının rahatsız olduğu belirlenmiştir.

$\mathrm{Bu}$ sonuçlara dayanarak postpartum dönemde uygulanan uterus masajının özellikle "transabdominal fundus masajı"nın ağrıy1 azaltmada etkili olduğu, kadını rahatlatttığ 1 ve analjezik kullanım oranını azaltacağı düşünüldüğünde hemşirelik ve ebelik girișimi olarak kullanılabileceği söylenebilir. Ayrıca doğum sonu bakım uygulamalarında kanıta dayalı araştırmaların kullanılması hem hemşirelik ve ebelik bakım kalitesini hem de kadının konforunu olumlu yönde etkileyecektir. 


\section{KAYNAKLAR}

1. Ramasamy P, Suzan HL. Effectiveness of Selected Nursing Measures on Level of After Birth Pain Among Primipara Mothers. Journal of Gynecology and Obstetrics, 2014; 2(6): 100-105.

2. Taşkın L. Doğum Sonu Dönem. Doğum ve Kadın Să̆lığı Hemşireliği. Genişletilmiş XIV Baskl, Sistem Ofset Matbaacılık, Ankara, 2015; s:455-523.

3. Gölbaşı Z. Postpartum Komplikasyonlar/Riskli Durumlar. Şirin A, Kavlak O, editör. Kadın Să̆lı̆̆l. 1. Baskı. Istanbul: Bediray Basin Yaylncilık 2008; s.790-809.

4. Deussen AR. Ashwood P, Martis R. Analgesia For Relief of Pain Due to Uterine Cramping/Involution After Birth (Review). Copyright, The Cochrane Collaboration. Published by JohnWiley \& Sons, Ltd. 2011, (http://www. update-software.com, Erişim tarihi: 08 Eylül 2015).

5. Holdrocft A. Postpartum Lower Abdominal Pain. Current Review of Pain, 1999;3:137-43.

6. Holdrocft A, Snivdongs S, Cason A, Dore C, Berkely K. Pain and Uterine Contractions During Breast Feeding in the Immediate Post-Partum Period Increase with Parity. Pain, 2003;104:589-96.

7. Mucuk S, Başer M. Doğum A ğrısını Hafifletmede Kullanılan Tensel Uyarlma Yöntemleri. Atatürk Üniversitesi Hemşirelik Yüksekokulu Dergisi, 2009;12 (3):61-6.

8. Yaju Y, Kataoka Y, Eto H, Horiuchi S, Mori R. Prophylactic Interventions AfterDelivery of Placenta For Reducing Bleeding During The Postnatal Period (Review). Copyright (C) 2013 The Cochrane Collaboration. Published by JohnWiley \& Sons, Ltd.

9. Lalonde A, Daviss BA, Acosta A, Herschderfer K. Postpartum Hemorrhage Today: ICM/FIGO initiative 2004-2006. International Journal of Gynecology and Obstetrics, 2006;94:243-53.
10. Beal MW. Acupuncture and Acupressure Applications to Women's Reproductive Health Care. J Nurse Midwifery 1999; 44(3):217-30.

11. Simkin PP, O'Hara MA. Nonpharmacologic Relief Pain Duringlabor: Systematic Reviews of Five Methods. Am J Obstetgynecol, 2002;186(5):131-159.

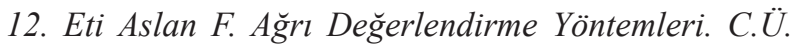
Hemşirelik Yüksekokulu Dergisi, 2002; 6(1):9-16.

13. Büyüköztürk Ş. Sosyal Bilimler Iç̧in Veri Analizi El Kitabı. 11. Baskı. Pegem Akademi; 2010: s.1-196.

14. Coşkun A, Aslan, E. Doğum Sonu Dönem. Coşkun $A M$, editör. Kadın Sağlı̆̆ ve Hastalıklarl Hemşireliği El Kitabı. Koç Üniversitesi Yayınları. 1. Baskı Istanbul: 2012. s.237-293.

15. Damrongrucktham C, Kimpee S. Toskukao T. "Effects of Hand Reflexology on Level of Pain in Abdominal Surgery Patients", Journal of Nursing Science, 2009;27 (2):49-58.

16. Jangsten E, Strand R, Gomez Freitas EG, Hellström AL, Johansson A, Bergström S. Women's Perceptions of Pain and Discomfort After Childbirth in Angola. African Journal of Reproductive Health, 2005;9(3):149-60.

17. Mogren IM. BMI, Pain and Hyper-Mobility are Determinants of Long-Term Outcome for Women with Low Back Pain and Pelvic Pain During Pregnancy. Eur Spine J, 2006, 15(7):1093-1102.

18. Mogren IM. Physical Activity and Persistent Low Back Pain and Pelvic Pain Post Partum. BMC Public Health, 2008;8(417):1-5.

19. Özdemir F, Karaoğlu L, Özfirat Ö. Malatya İl Merkezinde Yaşayan Bireylerde Boyun, Sirt ve Bel Ăgrısı Prevalanslart ve Etkileyen Faktörler, A ̈̆rı, 2013;25(1):27-35. 